\title{
África y el Atlántico a través de las islas Canarias durante la agregación portuguesa a la Monarquía Hispánica: espacios de frontera y construcción atlántica
}

\section{Africa and the Atlantic through the Canary Islands during the Portuguese Integration into the Hispanic Monarchy: Frontier Spaces and Atlantic Construction}

\author{
JAVIER LUIS ÁLVAREZ SANTOS \\ Universidad Nueva de Lisboa, Portugal
}

Resumen: En esta investigación se analiza el desarrollo de las relaciones socioeconómicas transatlánticas del continente africano durante el periodo de la agregación de Portugal a la Monarquía Hispánica. El objetivo es abordar el encajamiento de África en las dinámicas oceánicas durante la consolidación del mundo atlántico a partir del análisis, como objeto de estudio, de las islas de la Macaronesia como nexo entre el continente vecino y los territorios circundantes. El propósito de este trabajo, sustentado en el examen de fuentes documentales coetáneas y en la crítica historiográfica, es conocer las

Recepción: 6 de julio de 2020. / Aceptación: 3 de septiembre de 2020.

D.R. ${ }^{\circ}$ 2021. Estudios de Asia y África Licencia Creative Commons Atribución-NoComercial-SinDerivar (CC BY-NC-ND) 4.0 Internacional 
relaciones transfronterizas que conectaron el África atlántica con otros territorios vinculados al océano a partir de redes mercantiles transnacionales.

Palabras clave: Atlántico; Canarias; África; Monarquía Hispánica; frontera.

Abstract: This research considers how the African continent's transatlantic socioeconomic relations developed during the period of the Portuguese integration into the Hispanic monarchy. This paper sets out to examine Africa's engagement in transoceanic dynamics during consolidation of the Atlantic world based on the analysis, as an object of study, of the Macaronesian islands as a link between the neighbouring continent and the surrounding territories. The purpose of this research, based on the analysis of contemporary documentary sources and on historiographic criticism, is to explore the cross-border relations that connected Atlantic Africa with other oceanic territories through transnational trading networks.

Keywords: Atlantic; Canary Islands; Africa; Hispanic monarchy; frontier.

\section{Introducción: problemática de estudio y metodología empleada}

Esta investigación analiza la inserción de África en el Atlántico ibérico durante el periodo denominado Unión Ibérica, a partir de las relaciones transfronterizas que se establecieron entre este continente y los espacios intraatlánticos: las islas. Metodológicamente, se parte de una crítica historiográfica para avanzar en el análisis del archipiélago canario como nexo entre África y el Atlántico con la finalidad de desentrañar la agencia de las redes atlánticas transnacionales. El estudio está basado en el análisis multifocal de fuentes primarias, tanto españolas como portuguesas, locales y nacionales. Como resultado se identifica la interacción entre el continente africano y las islas como parte de una construcción atlántica común. 


\section{Los vínculos atlánticos del continente africano a través de Canarias: una revisión historiográfica}

Sobre el Atlántico y en los espacios intrínsecos del océano brotaron tanto nuevas leyendas y mitos como planteamientos racionalistas que permitieron apreciar esta entidad geográfica desde diferentes perspectivas y disciplinas; siempre desde la percepción personal de quien se acercaba a imaginar este espacio. Desde mediados del siglo xx, la historiografía se interesó por la reconstrucción del pasado del mundo atlántico. Este acercamiento a la conformación del océano constituyó una categoría analítica, sustentada en una perspectiva europea desde sus orígenes. En esta aproximación, el tratamiento giraba en torno al conocimiento cartográfico, naval, comercial, militar, de política de expansión, explotación económica, intercambio biológico e interacción cultural (Santana 2014, 11). Con base en esta idea primigenia, el Atlántico llegó a concebirse como "el océano interior de la civilización occidental” (Armitage 2004, 11).

Frente a la historia nacional o nacionalista de los años veinte, amaneció una historia transnacional. No obstante, ni África ni los africanos tenían cabida en esta definición de "civilización”, excepto si se mencionaba el comercio de esclavos en tanto que fuese de interés para sustentar la historia de Occidente. Ciertamente, hasta tiempos muy recientes, la historiografía sobre el Atlántico se centró en estrechar los lazos entre América del Norte y Europa bajo el cuño de "civilización”, y dejó de lado no sólo el continente africano, sino también toda América Latina.

La historiografía anglosajona sobre el Atlántico ha puesto el acento, en su metodología de análisis, en los flujos y los movimientos ligados al comercio de esclavos. Asimismo, la historiografía ibérica se ha centrado en la trata esclavista desde las antiguas colonias africanas como un proceso destacado en la articulación de espacios. A este respecto, la visión sobre África se ha vinculado más con América que con un análisis del propio continente. 
Actualmente, como señala Santana Pérez $(2014,19)$, no hay un análisis integral de la costa atlántica africana. Sin embargo, sí contamos con estudios sobre el Atlántico y su relación con algunas regiones africanas. Si bien África es el gran tema pendiente por integrar en la historia atlántica, recientemente se ha apostado por unos estudios atlánticos que van más allá del centralismo europeo y se adentran en las interacciones sociales y culturales, y han avanzado en las contribuciones africanas (Karras y Mcneill 1992, 5).

Como señala Valladares Ramírez $(2013,57)$, se conoce bien de la profusión literaria con que castellanos y portugueses escribieron sobre las distintas regiones de la Monarquía en África, América y Asia, pero es menos sabido que también lo hicieron, aunque en menor medida, sobre el imperio del "otro" durante la Unión Ibérica. Frutuoso es uno de estos pocos ejemplos de autores que tuvieron la ambición de describir el mundo ibérico que incorpora al otro lado de "la raya". Este cronista realiza un ejercicio narrativo que procura ser un compendio sobre el pasado de todas las islas. Integra los hechos de distintos espacios en un mismo relato y en un mismo discurso histórico. Su descripción no distingue la frontera política de uno u otro archipiélago, sino que agrega todas las islas y constituye una misma unidad independiente de la realidad política. ${ }^{1}$ Si bien no incorpora el continente africano a su narración, insiste en una historia común ancestral desde la integración de los territorios macaronésicos al conocimiento europeo y que se enfatiza con la agregación de los reinos ibéricos bajo la Monarquía Hispánica.

Ciertamente, desde el final de las exploraciones enriquinas hay crónicas de navegantes que trazaron un relato histórico

${ }^{1}$ Igual de relevante considera el citado historiador "estos importantes estudios sobre las relaciones textuales luso-castellanas [que] han privilegiado la dimensión peninsular en detrimento de la ultramarina. De hecho, muy poco se ha inquirido sobre las ocasiones en que lusos y castellanos se dieron a escudriñar el imperio del vecino y, en concreto, al fenómeno de haber fijado sus visiones sobre el papel” (Valladares Ramírez 2013, 57). 
que conectaba las islas Canarias con el continente africano ${ }^{2} \mathrm{y}$ noticias de misiones religiosas portuguesas hacia África que recalaron en el archipiélago castellano en una época anterior a la unión dinástica. ${ }^{3}$ Sin embargo, fue hasta el siglo XVIII cuando la tradicional visión marginal y local de las islas dio paso a lecturas más amplias en las que el archipiélago fue visto, ante todo, como un enclave estratégico en el Atlántico. Ejemplo destacado del empleo de esta perspectiva más universal aplicada a la historia de las islas lo encontramos en la figura de un erudito local descendiente de portugueses, José de Viera y Clavijo (1731-1813). ${ }^{4}$ En su obra, este ilustrado no titubea en ubicar las islas entre África y América, en el corazón del Atlántico. En una altura en que este océano ha dejado de ser un mar ibérico para ser un espacio abierto a todo tipo de naciones y navegantes, sitúa a Canarias, en un lugar destacado dentro de estas encrucijadas atlánticas. Más aún, este autor se adelanta a decir lo que ningún otro cronista con anterioridad se había atrevido a afirmar: "Estas islas pertenecen al África” (Viera 1950,17$).^{5}$

${ }^{2}$ En el relato del periplo africano de Alvise da Cadamosto de 1455 se indica que la expedición, antes de alcanzar la desembocadura del río Gambia y retornar a Portugal, había pasado por Madeira, Canarias y Cabo Verde (Aznar, Corbella y Tejera 2017, 21).

${ }^{3}$ En 1560, el jesuita Agostinho de Lacera informaba en una carta al rey de las novedades en su viaje con destino a Angola. En ella relataba su derrotero entre las islas, tanto castellanas como portuguesas, antes de arribar al continente africano: "Domingo luego siguiente, último de deziembre, amanecimos a vista de las Canarias, cõ que se continuó nuestra alegría, y a la tarde fuymos en paraje de la Gomera [...] y otro dia lunes, primero dia del año de 1560 dia de Jesu, nos visitó cõ su misericordia dándonos viento en popa con bonança, porque sin tormenta caminavamos un dia natural con otro a 50, 55 y 57 leguas, que era una prospera navigacion, hasta llegar a la isla de Santiago en Cabo Verde" (Brásio 1953, 453-454).

${ }^{4}$ Sobre la obra de José de Viera y Clavijo, véase la publicación de Juan Manuel Santana Pérez (2017).

${ }^{5}$ Éste es el título del primer capítulo del primer libro, si bien Viera y Clavijo no fue el primer cronista que insistió en la geografía africana de las islas. Aunque nunca estuvo en Canarias, Bartolomé de las Casas (1986), en su libro I, incluye un extenso relato titulado "Breve relación de la destrucción de África", cuyos cinco primeros capítulos están dedicados a Canarias, el sexto a Madeira y Porto Santo, y el décimo a Azores y Cabo Verde. 
Viera y Clavijo, el primer defensor de lo que podríamos llamar "atlantonacionalismo" (Martínez 2010, 150), inicia su narrativa histórica posicionando las islas en el mapa de los dominios de la Monarquía. Estos territorios insulares que se creían alejados se convierten en su discurso en el centro geográfico y geoestratégico del Atlántico de las naciones europeas: “Desde el seno del Mar Atlántico y en medio de aquellas felices Islas que sirven de primer meridiano y como puente a la comunicación de los dos mundos sujetos al glorioso imperio del mejor de los Reyes" (Viera 1950, 3).

Más aún, Viera y Clavijo reflexiona y comprende que las islas, unidas a Europa y a América por la política del Imperio y el comercio de los hombres de negocio, también se encuentran ligadas geográficamente a África, el tercer continente que clausura el espacio circunatlántico. ${ }^{6}$ Este territorio aparece como un elemento destacado de la historia que construye. A través de las expediciones canarias a las costas africanas, describe el medio geográfico, social y económico con el que se encuentran estos expedicionarios. Introduce en su relato la visión de los insulares sobre los grupos nativos y de los portugueses con los que se encuentran. Además, realiza una detallada descripción del litoral hasta el río Senegal.

Ciertamente, este historiador tenía una sensibilidad especial por los estudios africanos, ${ }^{7}$ además, con un mérito añadido: ser de los primeros investigadores que incorpora el continente africano a los estudios atlánticos. Antes incluso de que en la década de 1960 se extendiesen en Estados Unidos los estudios acerca de la esclavitud y el comercio de esclavos (Lucena 2010, 43).

6 "pues aunque no hay duda de que los volcanes las afligieron sobremanera en siglos más remotos; con todo, se echa muy bien de ver, por su interior organización [...]; y por otras muchas circunstancias, se echa muy bien de ver, digo, que ellas son parte de una tierra primitiva y original, como la del continente de África" (Viera 1942, 31-32).

7 También sobresale entre sus obras España y el África atlántica, publicada en Madrid en 1956. 
Cabe señalar que son escasas las investigaciones que se han hecho sobre los vínculos entre el dicho archipiélago y los enclaves portugueses en África. Más allá de los estudios transversales que, como los de Torrão (1991), conectaban ambos territorios a partir del tráfico de esclavos, hay pocas referencias bibliográficas. Curiosamente, el interés historiográfico en las relaciones entre Canarias y el África portuguesa durante la Edad Moderna es anterior incluso al de cualquier otro análisis de relaciones del archipiélago con el mundo luso. En 1978, Da Mota (1980) presentó en el tercer Coloquio de Historia Canario-Americana una ponencia sobre las expediciones canarias a Guinea durante el siglo Xvi. Este trabajo, que no tuvo continuidad en el tiempo, presentaba además otra gran novedad: se mostraba por primera vez en una publicación canaria documentación portuguesa dedicada a las relaciones Canarias-África. ${ }^{8}$

Habría que esperar a los inicios del siglo Xxi para que la historiografía, en este caso la canaria, retomase los trabajos sobre los contactos entre el archipiélago y el África portuguesa. ${ }^{9}$ Germán y Juan Manuel Santana Pérez, desde el área de historia moderna de la Universidad de Las Palmas, han venido promoviendo un análisis histórico que complementa la historia de los archipiélagos atlánticos y el continente vecino. ${ }^{10}$ De este interés historiográfico surgió La puerta afortunada (Santana

${ }^{8}$ En 1985 se publicó el libro Canarias y África: altibajos de una gravitación, en que el historiador Víctor Morales Lezcano se encargó de relatar un panorama general sobre el estado de los estudios históricos relativos a esa "gravitación" africana de Canarias. En ese sentido, para el periodo de la Edad Moderna, indicaba que si bien había habido avances sustanciales en las investigaciones sobre las relaciones entre el archipiélago y Berbería, afirmaba también que no entraría a abordar, "y es probable que nunca”, el papel de las islas como nexo en el comercio de esclavos entre África y América, por ser un tema desconocido (Morales, García y Pereira 1985, 16).

${ }^{9}$ Es cierto que no fue la primera vez que se trataron algunos temas de la historia canario-africana. Anaya Hernández (2001) ha estudiado los contactos con Berbería, y Lobo Cabrera (1998), la esclavitud en Canarias y las relaciones con Cabo Verde.

${ }^{10}$ Más recientemente, y a partir de la apuesta por esta línea de trabajo, por primera vez se ha publicado en una revista del archipiélago un monográfico sobre la historia del África atlántica. Me refiero al número 14 de la revista Vegueta de la Universidad de Las Palmas. 
y Santana 2002). Desde una contextualización inédita en la historiografía insular, esta obra llega a construir una historia global desde la particularidad del análisis de un microespacio. ${ }^{11}$ Se trata de una historia circunatlántica que supera los límites nacionales y las clásicas fronteras espaciales para centrarse en la coherente afinidad de vínculos entre ambas regiones - canaria y africana- en el espacio doméstico que representa el Atlántico.

En un trabajo más reciente, Juan Manuel Santana Pérez (2012) da relevancia a la posición de las islas de la Macaronesia en las dinámicas atlánticas. En este sentido, plantea cuatro vértices en las relaciones circunatlánticas. A los tradicionales espacios comerciales europeos, americanos y africanos, este historiador incorpora las islas atlánticas como cuarta área relacionante. Dota, en consecuencia, a los territorios insulares de un carácter propio y unitario (Santana 2012, 126).

A diferencia de otros estudios, este historiador enfatiza e integra el análisis de las relaciones mercantiles de las islas con el continente africano, concebido éste como un espacio activo en esta sinergia atlántica. Expone Santana Pérez múltiples rutas comerciales transoceánicas. En una de ellas, las embarcaciones que partían hacia África no se dirigían hacia América, sino que recalaban en las islas. Por tanto, infiere que fueron los territorios insulares las plazas redistribuidoras de productos africanos -especialmente de esclavos- hacia América y Europa (Santana 2012, 127).

Entre la multiplicidad de caminos atlánticos que describe, Santana Pérez propone un novedoso triángulo comercial formado por la América portuguesa, África y las islas. Algunas naves que salían de Brasil arribaban a territorios africanos para, desde

${ }^{11}$ Así lo reflejan los propios autores: "los estudios sobre este continente cuentan en el Antiguo Régimen con algunos trabajos interesantes, casi siempre referidos a alguna zona concreta. Pero existe una ausencia en las investigaciones sobre la relación global de Canarias con el conjunto de África a lo largo de un periodo de tiempo prolongado" (Santana y Santana 2002, 8). 
allí, dirigirse a Canarias, por lo que a las islas llegaban productos tanto americanos como africanos. Recalca nuevamente, a partir de la explicación de este derrotero, la naturaleza redistributiva del archipiélago.

\section{La documentación notarial como fuente de estudio para la reconstrucción de vínculos atlántico-africanos e insulares}

He tratado las cuestiones que surgen a partir de una visión multifocal de la concomitancia entre el cosmos africano y el universo ibérico en el Atlántico a partir de distintas fuentes de diverso origen. La documentación primaria constituye una herramienta indispensable para desarrollar un estudio integral en lo social, lo económico y lo cultural, así como para elaborar un análisis tanto desde la perspectiva regia como desde el ámbito local y para confrontar la interpretación que construyen la metrópoli y las islas sobre nuestro objeto de estudio.

Metodológicamente, la investigación de archivo realizada para este estudio parte del análisis de la documentación notarial, tanto canaria como portuguesa. Por el tipo de información que aporta y la variedad de asuntos que trata, la documentación notarial para la isla de Tenerife es uno de los pilares sobre los que se sustenta esta investigación. ${ }^{12}$ Con todas las limitaciones y las reservas, estas escrituras muestran la cotidianidad del individuo, su relación con el medio y la interacción con otros miembros de la sociedad. En el caso de los registros notariales insulares, he analizado las escrituras para un periodo más amplio que el de la propia agregación portuguesa, entre 1575 y 1650, con el objetivo de profundizar en los antecedentes y

${ }^{12}$ Escogí Tenerife por dos cuestiones metodológicas. En primer lugar, el buen estado de conservación de la documentación para esta isla frente a la de otros territorios insulares del archipiélago. En segundo lugar, por ser la isla con mayor proyección internacional durante esta época de la Edad Moderna. 
las repercusiones para las relaciones canario-africanas durante esta unión política luso-castellana. ${ }^{13}$

Para abordar esta cronología tan extensa, realicé dos tipos de catas en los legajos notariales. La primera consistió en analizar la documentación de todas las escribanías de la isla para los siguientes años específicos: 1575, 1576, 1587, 1588, 1603, 1604, 1625,1626 y 1650 . Esta selección busca ser una muestra de las fluctuantes relaciones entre la isla de Tenerife y el Atlántico ibérico, más concretamente con África.

La segunda cata fue realizada a través de una selección de las escribanías más relevantes de la isla para obtener una muestra representativa del periodo cronológico por estudiar. Así, procuré ciertos escribanos que perdurasen en el tiempo con el objetivo de obtener una visión temporal consecutiva y de mayor recorrido. ${ }^{14}$

En el caso de la documentación portuguesa, decidí consultar los Cartórios notariais conservados para la ciudad de Lisboa. Siguiendo con la metodología, he consultado aquellos fondos que se han conservado para el periodo de estudio. ${ }^{15} \mathrm{Se}$ trata de documentación esencialmente sobre asuntos de tipo económico: compraventas, letras, poderes, fletes, obligaciones, créditos, etcétera.

Lisboa fue uno de los puertos europeos, junto con los de Sevilla y Amberes, más activos durante el periodo de análisis. Lisboa era la cabeza del reino de Portugal y un centro mercantil de primer orden a escala mundial (Veríssimo 1979, 280), por lo que la consulta de la documentación primera de esta urbe reforzaría nuestra visión acerca de la organización económica del Atlántico y, sobre todo, de las redes comerciales de origen

${ }^{13}$ Los legajos consultados se custodian en el Archivo Histórico Provincial de Santa Cruz de Tenerife (AHPSCT).

${ }^{14}$ Las escribanías de Rodrigo de Vera Acebedo (1608-1612) y Salvador Fernández de Villarreal (1613-1644) para el caso de La Laguna, y la de Salvador Pérez de Guzmán (1608-1630) para Garachico.

${ }^{15}$ Esta documentación también ha sufrido importantes pérdidas a lo largo del tiempo, por ejemplo, con el terremoto de 1755, que tuvo las consecuencias más nefastas para estos fondos. 
portugués que actúan estrechamente entre África y Canarias. Estas islas estuvieron, desde la conquista y la ocupación castellanas, insertas en los intereses portugueses y en la órbita del comercio atlántico portugués, en particular como nexo con su vecino africano. De esta manera, las expectativas de negocio en el mercado canario fueron un polo constante de atracción para banqueros, inversores y grandes comerciantes. No obstante, fue a partir de la unión dinástica cuando se produjo la agregación definitiva de las islas castellanas a las actividades socioeconómicas vinculadas al continente africano. En primer lugar, en el contexto internacional, se produjo la consolidación del espacio atlántico. En segundo, y ligada a este dinamismo oceánico, se consolidó una economía de exportación insular hacia ultramar.

Más allá de esta tipología, se observa una tupida red mercantil que circundaba las distintas orillas del Atlántico, en las que se insertan las islas Canarias. Era un derrotero atlántico no bidireccional y que englobaba a buena parte de las regiones que rodean el océano; se invertía el beneficio de este negocio en otras mercancías que eran reexportadas a Europa, y cuyo lucro final volvía a ser empleado en productos que deambulaban en el Atlántico. ${ }^{16}$

\section{La red mercantil transnacional entre Canarias, África y el Atlántico}

Debido a la carencia de fuentes, tanto canarias como portuguesas, este análisis de redes entre el archipiélago y el continente africano parte de la reconstrucción de los vínculos transfronterizos a partir de un estudio de caso. La figura de Juan de Vega, un importante comerciante portugués de esclavos que se

${ }^{16}$ En este sentido, concuerdo con el planteamiento de Alencastro (2001), quien defiende -frente al clásico esquema dual metrópoli/colonia- un modelo basado en espacios y mercados interdependientes, con múltiples y complejas jerarquías. 
estableció en Tenerife, es el eje que sirve de guía para tratar las relaciones entre los dos espacios atlánticos.

Procedente de Cabo Verde, este individuo se asentó en la isla en la década de 1580. En 1584 adquirió el ingenio azucarero del valle de Güímar. Diversificó la producción y reinvirtió los beneficios de la hacienda tanto en la economía local como en el comercio internacional atlántico. Esta reorganización permitió a Juan de Vega sacar cierto rédito de la producción azucarera, a pesar de estar en retroceso el cultivo de la caña de azúcar en la isla en esa época. Así, en 1587 afirmaba que su hacienda producía 120 arrobas, las cuales había rematado al flamenco Pedro Blanco. Sin embargo, estas arrobas aún no se habían terminado de trabajar, por lo que el portugués tuvo que hipotecar toda la producción y los esclavos que tenía en el heredamiento. ${ }^{17}$

Al mismo tiempo que continuaba con el cultivo de la caña de azúcar en su hacienda, otorgaba nuevas medianerías asociadas al trabajo de la viña. Por tanto, Juan de Vega era consciente del cambio económico que se estaba produciendo en la isla y apostó por reconvertir el heredamiento y fomentar la producción vitivinícola. ${ }^{18}$ No obstante, la principal actividad a la que se dedicaba este portugués era la trata de esclavos. Las escrituras estudiadas indican que fue el principal mercader de esclavos en la isla durante el último cuarto del siglo XVI, que efectuaba $71.5 \%$ de estos negocios que he documentado. Desde Cabo Verde introducía principalmente varones de entre 15 y 26 años a un precio medio de 900 reales por individuo.

La mayor parte de los compradores eran miembros de la élite local, como el escribano Francisco de Mesa o el regidor Diego de Arguijo. Probablemente, con la importación de esclavos a Tenerife pretendió cancelar parte de las deudas que arrastraba el heredamiento. Precisamente, a Diego de Arguijo

${ }^{17}$ AHPSCT, leg. 1168, sin folio.

${ }^{18}$ Valga como ejemplo el tributo que concedió a medias a Gaspar Hernández, vecino del valle de Güímar, para plantar viñas. АНРSCT, leg. 666, fo 277. 
le entregó, por una deuda contraída en la heredad de Güímar, una esclava negra de 14 años y un hombre de 24 años por un valor de 100 doblas y 900 reales respectivamente. ${ }^{19}$

Del mismo modo, también reinvirtió los beneficios obtenidos del ingenio en el comercio internacional. Ejemplo de este entramado atlántico es el compromiso que adquirió con el mercader Pedro de Salas para comprar en la isla de Santiago una esclava negra de 20 a 30 años y un varón de 15 a 20 años. ${ }^{20}$

Es posible que las demás deudas con los acreedores de la hacienda se hayan liquidado de la misma forma. Al hijo del anterior propietario, Francisco de Alarcón, le traspasó 2100 ducados que tenía en una compañía para llevar esclavos de Guinea a Indias en una nao surta en el puerto de Santa Cruz, ${ }^{21}$ la misma cifra por la que se había tasado la parte de la hacienda que Juan de Vega le había comprado. No obstante, no debió haber sido suficiente. A finales de 1588, estando el portugués en Cabo Verde, otorgó un poder al regidor Juan de Herrera para que interviniera en una ejecución sobre "cierta cantidad de maravedís" que le debía a Francisco de Alarcón. ${ }^{22}$

Juan de Vega aprovechaba esta red entre los dos archipiélagos para establecer lazos y convertirse en el apoderado de los principales hombres de la sociedad tinerfeña en territorio caboverdiano. De esta manera, recibía poderes de la élite local para actuar en este espacio insular portugués. ${ }^{23}$

De igual modo, participó en el mercado atlántico castellano a partir de la correspondencia que mantenía con el puerto de Sevilla. Así, formó una compañía con un mercader y un maestre de navío vecinos de la ciudad hispalense. En este negocio, Juan

\footnotetext{
${ }^{19}$ AHPSCT, leg. 669, fos 324 y $352 \mathrm{v}$.

${ }^{20}$ AHPSCT, leg. 1512, fo 768.

${ }^{21}$ AHPSCT, leg. 666, fo 663v.

22 AHPSCT, leg. 1514, fo 209.

${ }^{23}$ Así, Juan de Súrega le otorgó un poder para que cobrase de Gonzalo Rodríguez, vecino de Tenerife y residente en Santiago, las ganancias que le pertenecían. AHPSCT,
} leg. 1512, fo 760 . 
de Vega se encargaba de los arreglos de la carabela, así como de cargar las pipas de vino y despachar el almojarifazgo. ${ }^{24}$

Para desarrollar esta compleja red mercantil, era necesario haber consolidado unos vínculos sociales y familiares distribuidos en las distintas plazas atlánticas con el fin de satisfacer las demandas del circuito comercial. De este modo, su yerno Juan de Spíndola Escorcio - asimismo vecino de Cabo Verde y estante en Tenerife- actuó en la isla como apoderado suyo en su ausencia. 25

Además de fortalecer los lazos parentales, también se relacionó con otros portugueses asentados en el archipiélago. El nexo más relevante es el que mantuvo con el comerciante portugués Pedro Afonso Mazuelos, quien le suministraba vino que luego Juan de Vega se encargaba de comercializar en el exterior. Coincidieron estos acuerdos mercantiles entre ambos con el periodo en el que Pedro Afonso ostentaba el cargo de almojarife, por lo que es probable que participasen juntos en esta red mercantil. A este respecto, Pedro Afonso fue el encargado de cobrar los derechos del almojarifazgo en el referido contrato entre los comerciantes sevillanos y Juan de Vega. Por consiguiente, estos dos individuos tenían intereses comunes y participaban del mismo entramado económico insular y atlántico. ${ }^{26}$

Estos estrechos vínculos socioeconómicos entre individuos que visibilizan los lazos entre Canarias y África se fueron perdiendo conforme se aproximaba el final de la centuria. A partir de 1590, Juan de Vega y sus apoderados fueron devolviendo la propiedad a la familia de los antiguos propietarios.

${ }^{24}$ AHPSCT, leg. 666, fo $712 \mathrm{v}$.

${ }^{25}$ De esta manera, en 1588 le otorgó un poder para que actuase en su nombre en distintos negocios. AHPSCT, leg. 1511, fo 212.

${ }^{26}$ Probablemente, Pedro Afonso Mazuelos también habría estado involucrado en el comercio esclavista, o por lo menos mantenía vínculos con los miembros más destacados de este negocio. Así, en 1594 recibió un finiquito de una letra que había pasado sobre Diego Anrique, arrendador del contrato de Cabo Verde. Arquivo Nacional da Torre do Tombo (ANTT), $7^{\circ}$ Cartório Notarial de Lisboa-Ofício A, Livro 1584 , fo 35 . 
En definitiva, estos lazos en el Atlántico, especialmente entre el continente africano y las islas, trascendieron y desbordaron los intereses individuales. Estos contactos construyeron vínculos duraderos basados en el constante flujo de mercancías y personas, así como en la transferencia de conocimientos e ideas entre ambos espacios y sociedades.

\section{Las islas en el comercio transnacional de esclavos africanos}

He localizado un total de 57 contratos de compraventa de esclavos, lo que supone el comercio de 96 individuos. Estas transacciones, según se desprende de la documentación consultada, aumentaron conforme avanzaba el siglo XVII. Así, este tipo de acuerdos se repartieron de la siguiente forma, según las catas bianuales realizadas: $1575-1576$, sólo representaron 16\% de estas escrituras de compraventa, mientras que para los años 1587 y1588, esa cantidad se elevó a 25\%. Finalmente, durante el bienio 1625-1626 se efectuaron más de la mitad de estos acuerdos. Esta misma tendencia progresiva se observa en el número de esclavos vendidos: mientras que entre 1575 y 1576 se comercializaron únicamente seis, entre 1625 y 1626 se traficó con 42 individuos.

Sólo cuatro del total de las escrituras se refieren a la venta de más de un esclavo, por lo que entiendo que estos acuerdos se concertaban directamente entre el vendedor y el futuro propietario, sin que la documentación indique un comercio insular de esclavos a mayor escala que la que suponía el abastecimiento local y las adquisiciones personales.

En cuanto a los tratantes, eran en su mayor parte maestres $-40 \%-y$ mercaderes portugueses peninsulares y agentes lusos procedentes de Cabo Verde. Dentro de este colectivo, como ya se advirtió, sobresale el comerciante Juan de Vega Albarnás durante la década de 1580. Asimismo, también participaban en esta red de comercio esclavista desde Canarias individuos de 
otras comunidades no castellanas. De esta manera, a comienzos del siglo XVII, los hermanos Oflaque - de origen flamenco- se convirtieron en los agentes del arrendador de los contratos de Guinea, Jácome Fixer, en Tenerife y en Gran Canaria. ${ }^{27}$

Este mecanismo de compraventa de esclavos podía ir asociado a fórmulas contractuales mucho más complejas, como se advierte en el siguiente ejemplo. En 1626, el capitán Jorge Báez de Acevedo, en virtud de un poder de su hermano Sebastián Báez, tratante asentado en Luanda,

recibió del capitán Luis Lorenzo, alguacil mayor y regidor perpetuo de Tenerife, seiscientos reales de contado y tres pipas de vino despachadas, que costaron novecientos cuarenta y tres reales y ocho cajones con quince quintales, y una arroba y media de brea que costaron doscientos cuarenta y seis reales, y seis docenas de cordobanes zurrados de negro y blanco que hicieron mil ochenta y siete reales.

La referida cantidad era el resto de los 9850 reales que había cobrado de Luis Lorenzo, el maestre Cristóbal Álvarez y el piloto Domingo Pérez, los cuales aún debía al dicho Sebastián Báez de Acevedo por 14 esclavos, mujeres y varones, que le había remitido con los dichos mareantes. ${ }^{28}$ En resumidas cuentas, en esta transacción el vendedor, desde Luanda, utilizaba como apoderado a su hermano para cobrar en diversas mercancías parte de la venta de los esclavos que habían sido traídos con anterioridad por marineros portugueses. ${ }^{29}$

Cronológicamente, los esclavos procedían, durante las últimas décadas del siglo XVI, sobre todo de Guinea y Cabo Verde,

${ }^{27}$ En 1603, Cornieles Oflaque, en nombre de Jácome Fixer, otorgaba poderes generales a su hermano Jorge Oflaque, mercader asentado en Gran Canaria. AHPSCT, leg. 464, sin folio. En ese mismo año, el dicho arrendador de los contratos de Cabo Verde daba poderes para la isla de La Palma para que se cobrase por las mercadurías que había remitido a dicho lugar. ANTT, $1^{\circ}$ Cartório Notarial de Lisboa-Ofício A, Livro 1603, fo 91; ANTT, $1^{\circ}$ Cartório Notarial de Lisboa-Ofício $A$, Livro 1603, fo $132 \mathrm{v}$.

${ }^{28}$ AHPSCT, leg. 696, fo $159 \mathrm{v}$.

${ }^{29}$ El mismo tipo de transacción realizó el referido Jorge Báez con Antonio Díaz Moura, otro miembro destacado de la comunidad portuguesa de Tenerife. En esta ocasión, aunque no explicita el número de esclavos, se sabe que el montante ascendía a 11949 reales, que serían pagados en ocho pipas de vino. AHPSCT, leg. 2279, fo 408. 
pero con la entrada de la nueva centuria -coincidiendo con un aumento de este comercio en $74.5 \%$-, fueron sustituidos por los angoleños. Estos esclavos eran en su mayoría hombres de unos veinte años. Su coste solía ser de unos 770 reales, pero el valor variaba según su origen, sexo y edad. Así, los procedentes de Cabo Verde tenían un precio medio de 860 reales, mientras que los de Angola eran 16\% más baratos; los "indios de Brasil", aunque no eran tan solicitados, llegaban a alcanzar los 1000 reales. A su vez, las mujeres se vendían por un precio superior al de los varones, en torno a $20 \%$ más. Lo mismo ocurría por edades, ya que los veinteañeros eran $10 \%$ más caros que los que no habían cumplido los veinte años.

Estas fluctuaciones en el precio y en el origen de los esclavos se debían a factores exógenos a la isla. Por un lado, la América portuguesa estaba requiriendo una importante cantidad de mano de obra esclava para los ingenios. Además, la injerencia de los enemigos de la Monarquía Hispánica en el Atlántico, en especial tras la ocupación holandesa de Bahía y Pernambuco, contribuyó al aumento de los precios. ${ }^{30}$

Por otro lado, a comienzos del siglo XVII se produjo una restructuración de la ruta del comercio de esclavos. Durante la centuria anterior, los navíos negreros, con orígenes dispares, habían tenido a Cabo Verde como destino obligado para hacer el registro de los esclavos. Desde ahí, después de haber descargado las mercancías oriundas de Europa y de embarcar otras provenientes de la costa de África y de las propias islas, salían nuevamente en dirección a sus bases iniciales en la península ibérica (Torrão 1991, 265).

Sin embargo, este circuito se vio alterado debido a que los principales comerciantes negreros estaban interesados en

${ }^{30}$ En 1643, el Consejo de Guerra de Portugal elevaba una consulta al rey Juan IV en relación con las medidas a tomar para fomentar el comercio de Angola, dada la importancia del envío de esclavos a los ingenios de la América portuguesa y las dificultades que se tenía para este negocio como consecuencia de la invasión holandesa. Además, en esta misma consulta se indicaba que la dicha ocupación habría repercutido en el aumento del precio de los esclavos. AHU (Arquivo Histórico Ultramarino), Angola, Caixa 4, núm. 17. 
organizar de manera más eficaz el abastecimiento de esclavos a los territorios americanos administrados por la Corona de Castilla. Estos tratantes buscaban reducir el tiempo del viaje yendo directamente a la costa africana y así evitar posibles pérdidas en el número de esclavos cautivados. No obstante, los caboverdianos insistieron al rey en la necesidad de mantener este circuito porque, según afirmaban, en dichas islas portuguesas no producían ni pan, ni vino, ni aceite, ni herramientas, ni paños de vestir. Estos géneros de primera necesidad eran llevados por los "mercaderes de Lisboa, Setúbal, Algarve, isla de Madeira, Azores, Canarias y Castilla” (Domingues 1991, 134).

Martim Correia da Silva, en una carta remitida en 1559, informaba al rey de Portugal de cómo en Canarias había portugueses que, desde las propias islas castellanas, iban al rescate de esclavos a la costa africana sin licencia real (Brásio 1954, 219). Efectivamente, numerosas fueron las quejas que elevaron las autoridades de Cabo Verde sobre el empobrecimiento y la situación social en la isla de Santiago, una vez que "los navíos oriundos de Castilla y de las islas Canarias ya no pasaban por Santiago antes de ir a Guinea y a falta de lucro para el pago de los salarios". 31

Estas preocupaciones locales, que llegaron directa o indirectamente al conocimiento del poder central, vienen a demostrar cuán importante era el comercio con el exterior para las islas del Atlántico, pero al mismo tiempo dan cuenta de la flagrante debilidad y dependencia de factores exógenos (Domingues 1991, 135).

La transferencia de Santiago a Cacheu del grueso del abastecimiento de los navíos negreros se consolidó a partir de la segunda década del siglo XVII. Simplemente, el rey no podía perjudicar a los comerciantes establecidos en Santo Domingo ni tampoco impedir el establecimiento de rutas directas desde núm. 66.

${ }^{31}$ Carta del gobernador de Cabo Verde al rey en 1616. AHu, Cabo Verde, Caixa 1, 
este puerto a la América gobernada por la Corona castellana, pues la actividad de los mercaderes en este circuito atlántico era indispensable para mantener a la Monarquía. Tampoco el monarca pretendía, lógicamente, desagradar a los arrendadores del contrato, ya que realmente eran éstos quienes presionaban al poder central con el objetivo de fomentar el trato de Cacheu en detrimento de los de Ribeira Grande en Cabo Verde.

Afirma Torrão $(1995,112)$ que en realidad nunca hubo una voluntad verdaderamente efectiva, por parte de las autoridades de Madrid, de solucionar los problemas de los habitantes de Cabo Verde e impedir estas rutas de esclavos que se dirigían a Guinea sin pasar por Santiago con el fin de garantizarles su antiguo exclusivo comercio de resgate en los ríos de Guinea. Sin embargo, tampoco se manifestó desde la Corte ninguna actitud marcadamente provocadora contra los habitantes de estas islas. Por el contrario, la Corona intentaba cautivar al mismo tiempo a los insulares demostrando su completo acuerdo y comprensión hacia las súplicas y las peticiones de los habitantes de Santiago. Así, otorgó diversas provisiones reales que les eran favorables, pero no tuvieron su debido efecto. ${ }^{32} \mathrm{El}$ rey era consciente de este incumplimiento y lo aceptaba por razones de soberanía. No podía permitir perder el dominio de un espacio geográfico tan relevante en el Atlántico.

\section{Canarias como nexo entre África y el Atlántico ibérico}

Si bien las relaciones mercantiles entre Canarias y África fueron regulares y constantes, el volumen de este negocio fue menor que el desarrollado con otros espacios circunatlánticos (Santana y Santana 2002, 17). No obstante, no hay que des-

${ }^{32}$ En la de 1617 ordenaba el rey que "todos los navíos que partiesen de Castilla y de las islas Canarias en dirección a Guinea tenían la obligación de pasar por la isla de Santiago, donde deberían despachar sus productos, bajo pena de perderlos en beneficio de la Fazenda Real". AHU, Cabo Verde, Caixa 1, núm. 88. 
estimar el papel de las redes mercantiles que ligaban a África con Canarias en el sistema atlántico. Las islas eran uno de los nexos que vinculaban el continente africano con el americano. Por un lado, navíos procedentes de los enclaves portugueses en África recalaban en las ínsulas castellanas para intercambiar algunos géneros africanos, como pieles, por vinos canarios $y$, con esta nueva carga, continuaban hacia América (Santana 2012, 127). Por otro, algunas naves que salían de América, sobre todo del Brasil portugués, recalaban en territorios africanos, principalmente en Cabo Verde, para desde allí dirigirse a Canarias, por lo que llegaban con artículos tanto brasileños como africanos.

Insulares -canarios y portugueses- participaron en el tráfico de esclavos que pasaba por las islas con destino al Nuevo Mundo. Desde finales del siglo XvI, y principalmente durante las primeras décadas de la siguiente centuria, numerosas embarcaciones portuguesas hacían escala en la isla antes de continuar al continente africano y, desde allí, dirigirse a los territorios americanos administrados por la Corona de Casti1la. En Canarias, estas embarcaciones cargaban especialmente vinos que intercambiaban en el resgate de esclavos. De este modo, comerciantes asentados en Tenerife intervinieron en el comercio esclavista al incrementar el valor de los productos que llevaba el navío - en este caso el vino-, con los que los marineros y los agentes portugueses harían parte de la compra de los esclavos. Además, los comerciantes insulares que participaban en esta red se aseguraban igualmente un beneficio que se acrecentaba en la medida en que se reinvertía la cuantía inicial - aunque fuera en especie- en nuevos productos en diferentes mercados. Es decir, la venta de vinos en la isla no solía ser un acuerdo directamente vinculado al abastecimiento del navío que se dirigía a África. Por el contrario, se acostumbraba a constituir compañías con la finalidad de aumentar el valor de este negocio inicial a través de una fórmula comercial que se basaba en el intercambio continuo de mercancías entre plazas distantes y ávidas de estos productos exóticos. 
En este sentido, sirva como ejemplo el acuerdo de 1618 entre Bernardo Brago, vecino de Sevilla, y Antonio Álvarez Suárez, vecino de Lisboa, con Antonio Fernández Dayla, portugués residente en La Laguna. Este último suministraba 27 pipas de vino a la compañía, las cuales iban por cuenta y riesgo de Diego y Jorge Coronel, vecinos de Lisboa. ${ }^{33}$ Una vez que llegasen Bernardo y Antonio Álvarez a Luanda, debían intercambiar los caldos por esclavos, a los cuales llevarían a Nueva España. Ya en América, ellos o alguno de los agentes de la red debían registrar lo procedido de la venta de los esclavos en oro y plata en los galeones de Indias o, si esto no fuera posible, tenían que enviar el beneficio consignado a Sevilla o a Lisboa a nombre de los referidos Diego y Jorge Coronel..$^{34}$

Un año más tarde, el propio Antonio Fernández Dayla volvió a constituir una compañía similar con Diego y Jorge Coronel, en esta ocasión para invertir 20 pipas de vino en el resgate de esclavos en Cacheu para, posteriormente, enviar las piezas a Nueva España. Esta vez, ante el desconocimiento del escribano de quiénes eran los mareantes portugueses que iban a llevar a cabo dicho periplo, los implicados en el acuerdo presentaron como testigos a dos lusos miembros del Regimiento de la isla de Tenerife, al ya referido Tomás Pereira de Castro y a Cristóbal Salazar. Curiosamente, pocos días después de haberse cerrado este acuerdo, fueron los propios Tomás y Cristóbal quienes participaron en esta compañía, al contribuir cada uno con 17 y 27 pipas y media respectivamente. ${ }^{35}$

Como se observa, en este negocio desde la isla participaban destacados miembros de la élite insular. Entre éstos, los principales agentes portugueses establecidos e integrados en la sociedad local. Junto a ellos, también intervenían otros no cas-

33 Estos dos mercaderes, junto con su padre Héctor Coronel, tenían trato frecuente con Canarias. Años atrás, en 1619, habían reclamado a Antonio Fernández, vecino de Garachico, las deudas pendientes por dinero, mercancías y esclavos. ANTT, $1^{\circ}$ Cartório Notarial de Lisboa-Ofício A, Livro 1616, fo 63v.

${ }^{34}$ AHPSCT, leg. 1536, fo 416v.

${ }^{35}$ AHPSCT, leg. 1537, fos 329v, 349v y 354. 
tellanos establecidos en la isla. Así, también en 1619, Domingo de Boulmeau, mercader francés vecino de Tenerife, junto con Richarte Baqueman, comerciante flamenco en Lisboa, hicieron una compañía para llevar desde Santa Cruz de Tenerife a Luanda 22 pipas y media de vino. Lo procedido de la venta de los caldos en África sería invertido en esclavos que llevarían a Indias. Por último, el montante final de este negocio sería remitido a Sevilla a Gaspar González Noguera, uno de los agentes de esta red. ${ }^{36}$ En esta compañía también participaron Cristóbal Salazar y Tomás Pereira, que acrecentaron la cantidad de vinos suministrados a esta empresa con 27 y 20 pipas respectivamente. ${ }^{37}$

Se deduce, por tanto, que el circuito canario-africano durante este periodo tuvo especial incidencia, sobre todo si se considera la implicación de este comercio en el sistema atlántico. A pesar de la figura del juez de registro de Indias en Canarias, la competencia de estas autoridades no alcanzaba a los navíos que cargaban para Brasil, Cabo Verde y Guinea, por lo cual se prohibía a estos funcionarios hacer visitas a esas embarcaciones, ya que esto correspondía a la justicia ordinaria (Peraza 1977, 73). Sin embargo, en la práctica fueron constantes las disputas entre el juez de Indias y el Cabildo, que se acusaban mutuamente de interferir en los registros de las embarcaciones que hacían este circuito. ${ }^{38}$

De la misma manera, los lazos entre el comercio canario con América y el que se hacía con África generaron malestar en el monopolio sevillano. En 1611, el Consulado de Sevilla, favorecido por la Casa de Contratación, solicitó que los navíos que desde Portugal acudían a Canarias con el fin de cargar para Brasil, Angola y otras partes, no tomasen registro en las islas, sino en Sevilla.

Sobre esta organización multifocal del comercio atlántico se amoldaba una tupida red mercantil transnacional que, en el

${ }^{36}$ AHPSCT, leg. 1537, fo 516.

${ }^{37}$ AHPSCT, leg. 1537, fos 507 y 511.

${ }^{38}$ Archivo Municipal de La Laguna, A-XI, 2. 
caso de la establecida en Canarias, venía acompañada además de un proceso de integración social de estos foráneos con la élite insular. A partir del estudio de la familia Pereira de Castro se visibiliza este pacto ínsulo-atlántico. Tomás Pereira habría llegado a la isla en 1610 o 1611 para administrar los bienes del Adelantamiento de Canarias, y en 1618 consolidó su integración a la sociedad al contraer matrimonio con la hija de un regidor perpetuo de la isla (Fernández 2004, 277).

A partir de ese momento, Tomás Pereira compaginó los negocios de la red internacional con los intereses económicos de la isla, o por lo menos con una parte de su oligarquía. Desde Tenerife continuó tratando con sus familiares residentes en la Corte - Simón Pereira, Payo Rodríguez de Paz y Domingos Pereira- con el fin de que pudiesen asegurar el encabezamiento de las rentas reales para el año $1620 .{ }^{39} \mathrm{Al}$ mismo tiempo, enlazó esa red internacional con los miembros de la élite local al hacer a su yerno, Juan Carrasco, partícipe de sus negocios de exportación de vinos a Brasil en forma de compañía. ${ }^{40}$

Las actividades mercantiles que llevó a cabo se volvieron cada vez más complejas. Comerció con la América administrada por la Corona de Castilla y con África e, incluso, a veces hizo de nexo entre estos dos territorios. En 1618 le vendió cuatro esclavos negros a un maestre de navío que se dirigía a Nueva España, pero se trataba de una falsa transacción. Aunque la sociedad insular ya lo había aceptado como "vecino", no estaba aún reconocido como natural de la isla en otros territorios de Castilla. En ocasiones, se vio obligado a emplear ciertas argucias para comerciar con las Indias. En este caso, aunque la venta oficial de los esclavos había sido realizada a un navegante vecino del puerto de Santa Cruz, el riesgo, pero también los beneficios de la trata de esclavos en América, iban registrados a su nombre en la primera flota de la Carrera de Indias que regresase a Castilla. ${ }^{41}$ Se observa, por

\footnotetext{
${ }^{39}$ AHPSCT, leg. 1538, fo 535.

${ }^{40}$ AHPSCT, leg. 1538, fo 311.

${ }^{41}$ AHPSCT, leg. 1536, fo 345.
} 
tanto, una red transfronteriza en cuya articulación Canarias y África constituyeron dos pilares fundamentales que, en último término, fueron piezas esenciales para la consolidación del mundo atlántico.

\section{Consideraciones finales}

Las islas fueron uno de los vértices del espacio atlántico y, desde su posición estratégica, establecieron vínculos con otras regiones circundantes, entre ellas el África atlántica, lo que permitió integrar una economía local a los grandes circuitos atlánticos. Esta relación cisatlántica entre el espacio insular y su entorno favoreció el establecimiento de individuos no castellanos en el archipiélago castellano. En la taxonomía de las redes en las que participaban las islas no se premiaba el origen de sus miembros. Más bien se organizaban de forma parental, y adquirían sus miembros nuevas responsabilidades con la sociedad local al tiempo que mantenían sus intereses en un sistema mercantil más amplio: la economía atlántica. Aunque la impronta portuguesa predomine en estas relaciones que se articularon con o desde el archipiélago, la verdadera función de estos agentes lusos era ser el vínculo entre este espacio intraatlántico y los distintos espacios circundantes, y emplearon para ello sus contactos tanto en la isla como en otras plazas.

En definitiva, en estas redes en las que se integraban esos peñascos atlánticos se yuxtaponían intereses insulares y portugueses que hacían de las necesidades ajenas las suyas propias. Este análisis local es reflejo de la complejidad y la cantidad de relaciones, circuitos y contactos que se construyeron y entrelazaron en el Atlántico y que hicieron de este espacio una entidad policéntrica y relacionante a diferentes escalas, en diferentes ámbitos y con diversos intereses. Canarias y África forjaron estrechos lazos promovidos por la élite insular y por comerciantes foráneos que contribuyeron a la consolidación de un Atlántico dinámico y relacionante. 
Los mares marcan y los océanos aún más, al modelar la impresión del insular sobre el espacio que le rodea. La cercanía a África, las tradicionales relaciones con América y la dependencia de Europa se entremezclan en una única experiencia atlántica que configura la identidad cultural de las islas. "No estaría de más recordar aquí que el Océano recibió probablemente su nombre de las islas y no a la inversa", afirmaba el doctor Rumeu de Armas $(1995,9)$ refiriéndose a la obra de Heródoto.

Los archipiélagos son esos peones históricos cuyo valor fluctúa dependiendo del tipo de relación y del trato con el amplio espacio envolvente con el que interactúan, directa o indirectamente. Lo local -las islas-, al final, constituye un elemento más del sistema. Eso quiere decir que cualquier alteración introducida en alguna de sus partes provocará, antes o después, modificaciones adaptativas en el resto.

En el caso que nos ocupa, el Atlántico no puede ser considerado como "una gran e inmensa masa de agua polvorizada de islas" (Vieira 2006, 3), pues son dos elementos asociados e indivisibles en la tradición histórica. Las islas se comportan como elementos de unión, como intermediarios entre los litorales circundantes. En consecuencia, las tradicionales relaciones entre Canarias y África son una manifestación evidente de la construcción histórica del espacio atlántico común.

\section{Referencias}

Alencastro, Luiz Felipe de. 2001. O trato dos viventes. Formação do Brasil no Atlântico Sul, séculos XVI e XVII. São Paulo: Companhia das Letras.

Anaya HeRnández, Luis Alberto. 2001. "El corso berberisco y sus consecuencias: cautivos y renegados canarios". Anuario de Estudios Atlánticos 47: 17-42.

Armitage, David. 2004. “Tres conceptos de historia atlántica”. Revista de Occidente 281: 7-28. 
Aznar Vallejo, Eduardo, Dolores Corbella Díaz y Eduardo Tejera Gaspar. 2017. Los viajes africanos de Alvise Cadamosto. San Cristóbal de La Laguna: Instituto de Estudios Canarios.

BRÁsio, António, org. 1953. Monumenta Missionária Africana. Vol. 2: África Ocidental (1532-1569). Lisboa: Agência Geral de Ultramar. https://repositorio.ul.pt/handle/10451/34721

Brásio, António, org. 1954. Monumenta Missionária Africana. Vol. 4: África Ocidental (1469-1599). Suplemento aos séculos XV e XVI. Lisboa: Agência Geral de Ultramar. http://hdl.handle. net $/ 10451 / 34718$

Casas, Bartolomé de las. 1986. Historia de las Indias. Caracas: Biblioteca Ayacucho.

Da Mota, Avelino Texeira. 1980. "Viagens espanholas das Canárias à Guiné no século XVI, segundo documentos dos arquivos portugueses”. En III Coloquio de Historia Canario-Americana (1978), coordinado por Francisco Morales Padrón, 2: 219-249. Las Palmas de Gran Canaria: Cabildo de Gran Canaria.

Domingues, Ângela. 1991. "Administração e instituições: Transplante, adaptação, funcionamento". En História geral de Cabo Verde, coordinado por Maria Emília Madeira y Luís de Albuquerque, 1: 41-124. Lisboa: Instituto de Investigação Científica Tropical.

Fernández de Béthencourt, Francisco. 2004. Nobiliario de Canarias. Vol. 2. La Laguna: J. Régulo Ed.

Karras, Alan L. y John Robert Mcneill. 1992. Atlantic American Societies: From Columbus Through Abolition, 1492-1888. Londres: Routledge.

Lobo Cabrera, Manuel y Fernando Bruquetas de Castro. 1998. "Viajes y negocios de La Palma a Cabo Verde (1600-1650)". En XII Coloquio de Historia Canario-Americana (1996), coordinado por Francisco Morales Padrón, 2: 57-75. Las Palmas de Gran Canaria: Cabildo Insular de Gran Canaria.

Lucena Giraldo, Manuel. 2010. "La historia atlántica y la fundación del Nuevo Mundo". Anuario de Estudios Atlánticos 56: 39-60.

Martínez Hernández, Marcos. 2010. "Islas míticas en relación con Canarias”. Cuadernos de Filología Clásica. Estudios griegos e indoeuropeos 20: 139-158. https://revistas.ucm.es/index.php/ CFCG/article/view/CFCG1010110139A 
Morales Lezcano, Víctor, Vicente García Franco y Teresa Pereira Rodríguez. 1985. Canarias y África (altibajos de una gravitación). Las Palmas de Gran Canaria: Mancomunidad de Cabildos.

Peraza de Ayala, José. 1977. El régimen comercial de Canarias con las Indias en los siglos XVI, XVII y XVIII. Sevilla: Universidad de Sevilla. Rumeu de Armas, Antonio. 1955. "Presentación". Anuario de Estudios Atlánticos, núm. 1: 7-12. https://mdc.ulpgc.es/cdm/singleitem/ collection/aea/id/1168/rec/1

SANTANA PÉREZ, Germán. 2014. "El África Atlántica: la construcción de la historia atlántica desde la aportación africana”. Vegueta: Anuario de la Facultad de Geografía e Historia, núm. 14: 11-25.

Santana Pérez, Germán y Juan Manuel Santana Pérez. 2002. La puerta afortunada: Canarias en las relaciones hispano-africanas de los siglos XVII y XVIII. Madrid: Los Libros de la Catarata.

SAntana PÉREZ, Juan Manuel. 2012. "Islas atlánticas en el comercio entre América y África en el Antiguo Régimen”. Cuadernos Americanos [nueva época] 4, núm. 142: 113-135. http://www. cialc.unam.mx/cuadamer/textos/ca142-113.pdf

SANTANA PÉrez, Juan Manuel. 2017. "Viera y Clavijo: historiador ilustrado del Atlántico". História da Historiografia: International Journal of Theory and History of Historiography 10, núm. 23: 4363. https://doi.org/10.15848/hh.v0i23.1068

Torrão, Maria Manuel Ferraz. 1991. "Actividade comercial externa de Cabo Verde: organização, funcionamento, evolução”. En História geral de Cabo Verde, coordinado por Maria Emília Madeira y Luís de Albuquerque, 1: 237-345. Lisboa: Instituto de Investigação Científica Tropical.

TORRÃo, Maria Manuel. 1995. "Rotas comerciais, agentes económicos, meios de pagamento". En História geral de Cabo Verde, coordinado por Maria Emília Madeira, 2: 17-124. Lisboa: Instituto de Investigação Científica Tropical.

Valladares Ramírez, Rafael. 2013. "Vasallos que se observan. Opinión y escritura imperial bajo la Unión de Coronas (15801640)". En Descrição geral do reino do Peru, em particular de Lima, editado por Isabel Araújo Branco, Margarita Eva Rodríguez García y Teresa Lacerda, 55-68. Lisboa: Centro de História de Além-Mar.

Veríssimo Serrão, Joaquim. 1979. História de Portugal. Vol. 4, Governo dos reis espanhóis. (1580-1640). Lisboa: Verbo. 
VIEIRA, Alberto. 2006. Madeira y Canarias. Rutas de ida y vuelta [PDF]. Funchal: Centro de Estudos de História do Atlântico. https:// es.slideshare.net/AlbertoVieira/canarias-5737393

Viera y Clavijo, José de. 1942. Diccionario de historia natural de las Islas Canarias, o Índice alfabético descriptivo de sus tres reinos animal, vegetal y mineral. Santa Cruz de Tenerife: Imprenta Valentín Sanz.

Viera y Clavijo, José de. 1950. Noticias de la historia general de las Islas Canarias. Vol. 1, La descripción geográfica de todas. Santa Cruz de Tenerife: Goya Ediciones.

Javier Luis Álvarez Santos es doctor con mención internacional en historia moderna por la Universidad de La Laguna y la Universidade Nova de Lisboa. Ha ejercido la docencia en la Universidade Nova de Lisboa y en la Pontificia Universidad Católica del Perú. Es investigador junior en el Centro de $\mathrm{Hu}-$ manidades en Portugal, donde dirige el proyecto Emigration and Social Inclusion in Cape Verde and Canary Islands. Historical Analysis Towards Identity Building in Contact Areas, y coordina el subgrupo de investigación História do espaço ibérico e ibero-americano (séculos XV-XIX). Es miembro del proyecto de investigación europeo FAILURE, del programa de innovación Marie Skłodowska-Curie.

https://orcid.org/0000-0002-7845-6521 jlasantos@fcsh.unl.pt 